\title{
USO DO SOLO E ANÁLISE TEMPORAL DA OCORRÊNCIA DE VEGETAÇÃO NATURAL NA FAZENDA EXPERIMENTAL EDGARDIA, EM BOTUCATU-SP ${ }^{1}$
}

\author{
Luiz Alberto Blanco Jorge² e Maurício Scorsatto Sartori ${ }^{2}$
}

\begin{abstract}
RESUMO - Foram mapeados o uso do solo e as alterações das áreas de vegetação natural da Fazenda Experimental Edgardia, localizada em região de Cuesta no município de Botucatu-SP, em dois períodos (1978 e 1997), com o auxílio do sistema de informações geográficas ILWIS v.2.2 para Windows, de fotografia aérea e de imagens dos satélites Spot e Landsat-5. Cruzaram-se as informações de ocorrência da vegetação natural nas duas épocas, derivando-se um mapa temático que permitiu verificar a variação temporal das áreas dos fragmentos florestais, assim como foram observadas as associações da vegetação natural com a declividade e as unidades de solo. Analisado o intervalo de 19 anos, foram detectadas uma regeneração significativa de áreas de Floresta Estacional Semidecidual, na frente da Cuesta, em unidades de Neossolo Litólico, e uma pequena regeneração da tipologia cerradão, na depressão periférica, onde ocorrem solos de textura arenosa.
\end{abstract}

Palavras-chave: Uso do solo, vegetação natural e Sistema de Informações Geográficas (G.I.S.).

\section{LAND USE AND TEMPORAL ANALYSIS OF NATURAL VEGETATION AT EDGARDIA EXPERIMENTAL FARM - BOTUCATU-SP}

\begin{abstract}
The purpose of this paper was to study land use and the alterations of the natural vegetation at the Edgardia Experimental Farm, in Botucatu-SP, Brazil. Land use thematic maps for different dates (1978 and 1997) were derived from aerial photography, and Spot and Landsat-5 TM images. A G.I.S. program, ILWIS v.2.2 for Windows was used to generate spatial information. Variation in the occurrence of natural vegetation was assessed by overlaying the land use maps of both periods. This information was crossed with the slope and soil unit maps. There was a significant regeneration of the tropical moist seasonal forest fragments at the Botucatu Cuesta Front Range, and a little regeneration in the forest - savannah transition areas at the Peripheric Depression.
\end{abstract}

Key words: $\quad$ Land use, natural vegetation and Geographic Information System (G.I.S).

\section{INTRODUÇÃO}

A Fazenda Experimental Edgardia, unidade de ensino e pesquisa administrada pela UNESP / Campus de Botucatu-SP, localizada em área de Cuesta, inclui em seus limites cinco fragmentos de vegetação natural das tipologias Floresta Estacional Semidecidual e cerradão. Estes fragmentos são muito importantes no contexto do município de Botucatu e da região, em função: 1) da localização, uma vez que estão situados na Área de Proteção
Ambiental (APA) de Botucatu; 2) de seus tamanhos em comparação com a área média dos fragmentos na região da Cuesta de Botucatu, que é de aproximadamente 10 ha; e 3) da possibilidade de ligação, pela frente da Cuesta, com outros remanescentes, através de corredores de vegetação natural.

A inexistência de informações espaciais atualizadas, no que se refere aos fragmentos de vegetação natural da Fazenda Experimental Edgardia, quais sejam: 1) áreas e

1 Recebido para publicação em 20.12.2001.

Aceito para publicação em 6.11.2002.

2 Dep. Recursos Naturais - FCA/UNESP - Caixa Postal 237, 18603-970 Botucatu-SP, <blanco@fca.unesp.br>. 
limites dos remanescentes; 2) variação temporal (aumento ou diminuição das áreas); 3) vizinhança; e 4) interação com informações espaciais de variáveis ambientais, estimulou o desenvolvimento do presente estudo. Este tipo de trabalho é fundamental para o suporte de outras pesquisas, como aquelas relacionadas aos seguintes temas: levantamentos de flora e fauna, restauração da vegetação natural e desenvolvimento de um plano de manejo integrado para a Fazenda Experimental. Sendo assim, os objetivos específicos da pesquisa ficaram definidos da seguinte forma:

1. mapear o uso do solo e as áreas atuais dos fragmentos de vegetação natural da Fazenda Experimental Edgardia, a partir de imagens dos satélites SPOT e Landsat (imagens de 1997), com o auxílio de um sistema de informações geográficas (SIG);

2. digitalizar as informações de uso do solo e dos fragmentos de vegetação natural da Fazenda Experimental Edgardia, tendo como base uma fotografia aérea de
1978, com o auxílio de um sistema de informações geográficas (SIG);

3. cruzar as informações de uso do solo e da vegetação natural de dois períodos (1978 e 1997), no ambiente do sistema de informações geográficas (SIG); e

4. analisar as informações de mudanças da vegetação natural entre os dois períodos (1978 e 1997) com informações de classes de declividade e unidades de solo.

\section{MATERIAL E MÉTODOS}

\section{1. Área de Estudo}

A Fazenda Experimental Edgardia está localizada na bacia do rio Capivara, município de Botucatu (Figura 1), Estado de São Paulo, circunscrita pelas coordenadas geográficas $22^{\circ} 47^{\prime} 30^{\prime \prime}$ a $22^{\circ} 50^{\prime}$ de latitude $\mathrm{S}$, e $48^{\circ}$ $26^{\prime} 15^{\prime}$ ' a $48^{\circ} 22^{\prime} 30^{\prime}$ "de longitude W. Encontra-se a aproximadamente $8 \mathrm{~km}$ da sede do município.

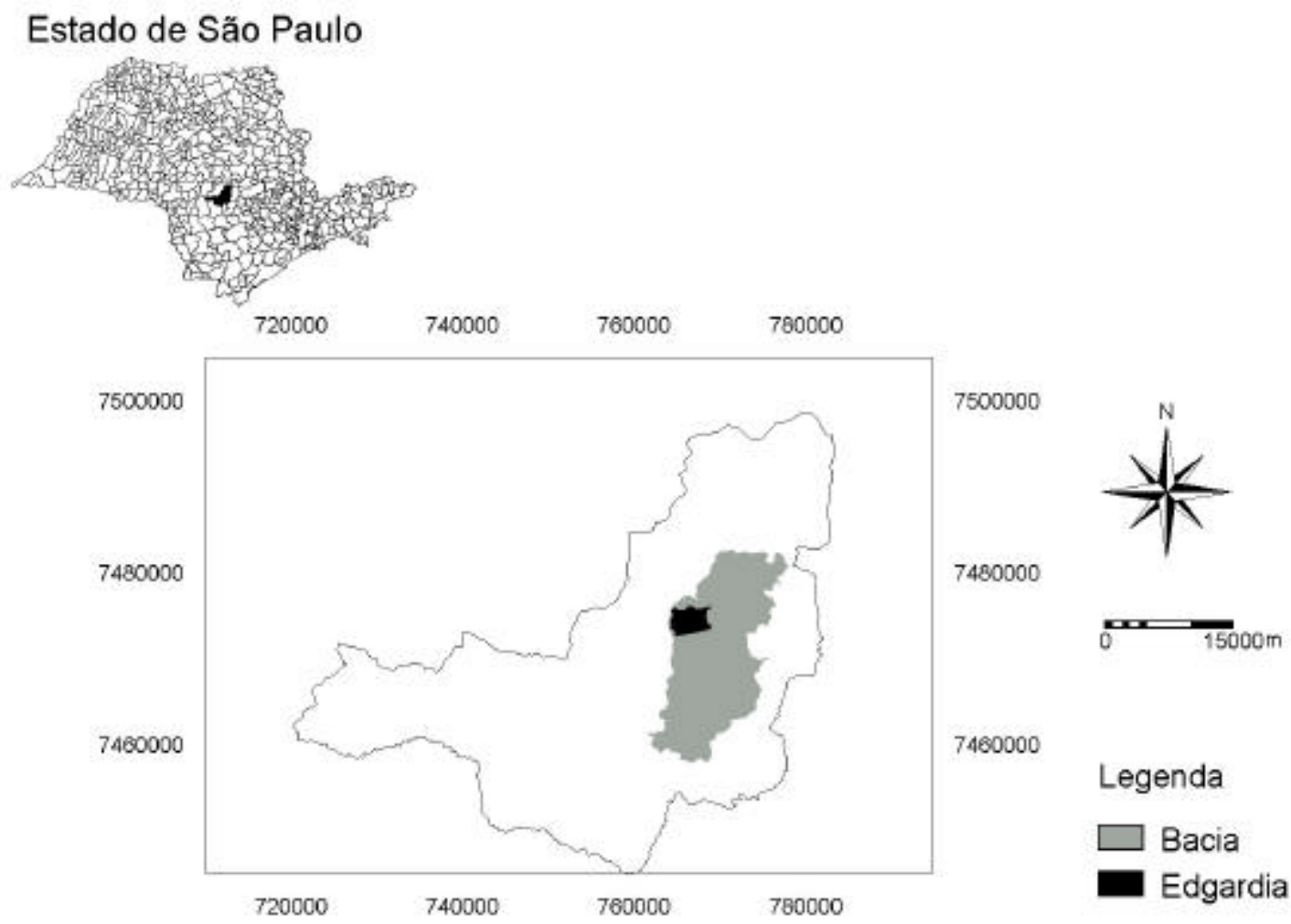

Figura 1 - Limites do município de Botucatu e localização da Fazenda Edgardia na bacia do rio Capivara.

Figure 1 - Boundaries of the Municipal District of Botucatu and location of Edgardia Experimental Farm at the Capivara river watershed. 
Na Fazenda Experimental Edgardia encontram-se duas províncias geomorfológicas: as Cuestas basálticas, referentes às ocorrências de rochas eruptivas básicas e a seus produtos de alteração, e a depressão periférica, compreendendo a área de presença de arenitos e de sedimentos aluviais, principalmente a leste da área, abrangendo a várzea da bacia do rio Capivara, rebaixada $250 \mathrm{~m} \mathrm{em}$ relação às Cuestas basálticas (Carvalho et al., 1991).

As menores altitudes da Fazenda Experimental Edgardia, em torno de 475 m, são encontradas na várzea do rio Capivara, onde o relevo é plano, comclasse de declive de 0 a $2 \%$, e se verifica a ocorrência de Neossolos Flúvicos, Gleissolos MelânicoseGleissolos Háplicos. Em direção à frente da Cuesta, ainda na depressão periférica, com altitude variando de 475 a 650 m, são comuns os relevos suave ondulado e ondulado (de 2 a $20 \%$ ), onde ocorrem as unidades de solos Neossolos Quartzarênicos órticos, Latossolos Vermelho-Amarelos, Latossolos Vermelhos, Argissolos Vermelhos, Nitossolos Vermelhos e Chernossolos Argilúvicos. Na Cuesta basáltica, com altitudes de 650 a 725 m, ocorrem os Neossolos Litólicos, em relevo forte ondulado, com declives de 20 a $40 \%$, e afloramentos de rocha em relevo escarpado, com declives superiores a 40\% (Carvalho et al., 1991). A Figura 2a e 2b apresenta, respectivamente, os mapas de classes de declividade e de unidades de solo da Fazenda Experimental Edgardia.

\section{a}
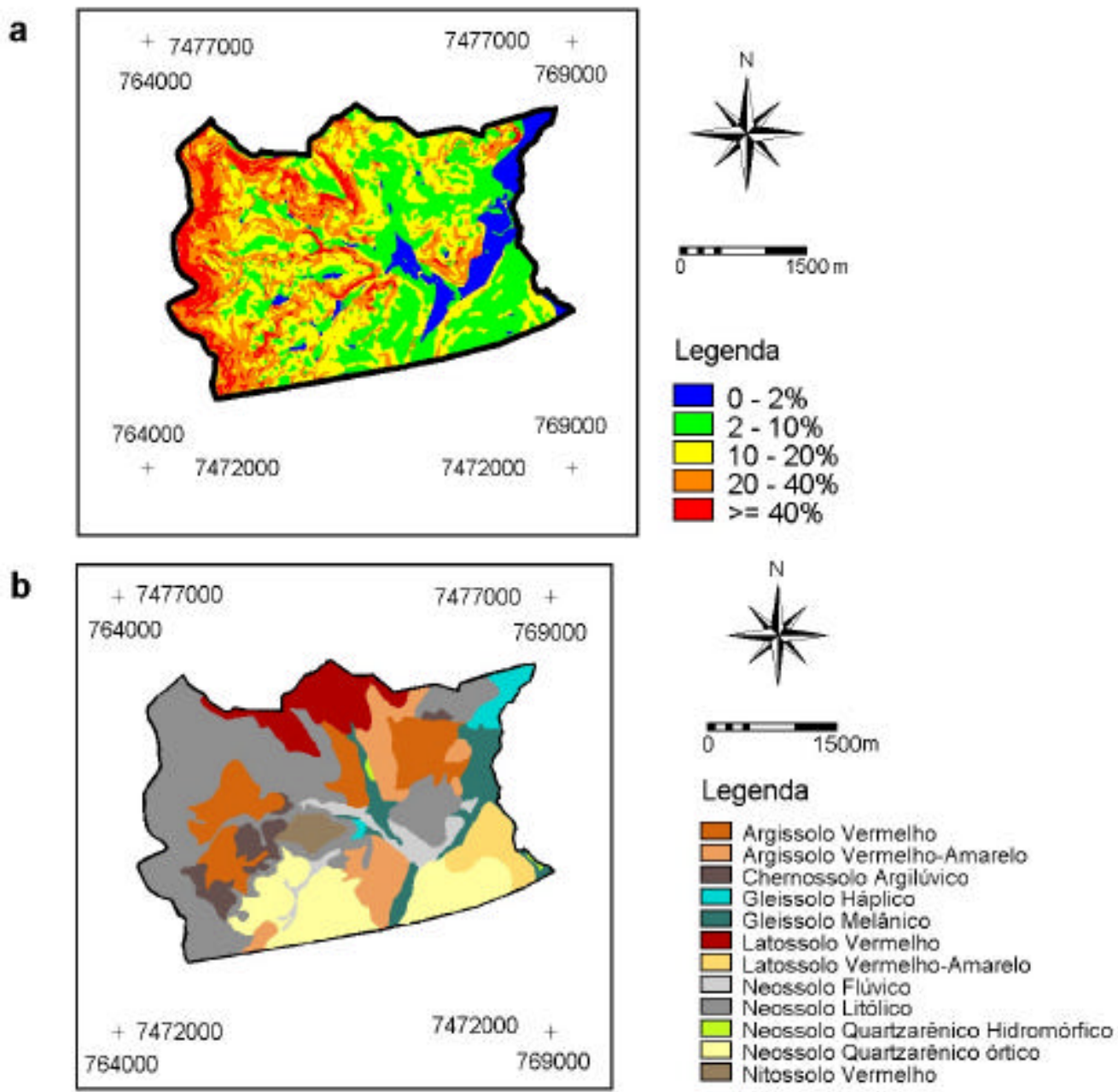

Figura 2 - a. Mapa de classes de declividade e b. mapa de unidades de solo (adaptado de Carvalho et al., 1991) da Fazenda Experimental Edgardia.

Figure 2 - a. Slope class map; b. Soil unit map of the Edgardia Experimental Farm. 
A principal tipologia vegetacional representada na área da Fazenda Experimental Edgardia é classificada como Floresta Estacional Semidecidual (Veloso, 1992), ocorrendo na área de transição da depressão periférica para a Cuesta basáltica, com remanescentes florestais pouco alterados ou que passaram por vários níveis de perturbações antrópicas. Podem também ser encontradas as tipologias Formação Pioneira Aluvial e Savana (Cerrado sensu lato) (Ortega \& Engel, 1992).

\subsection{Criação dos Mapas Temáticos de Uso do Solo e da Variação Temporal da Vegetação Natural}

Para criação do mapa temático da variação temporal da vegetação natural foram levantadas informações do histórico recente do uso do solo a partir de fotografia aérea de 1978 (vôo da Terrafoto S.A., escala 1:45000), e informações atualizadas sobre o uso do solo e vegetação natural a partir de imagens dos satélites SPOT e Landsat5. Foram elaborados os mapas de uso do solo para os dois momentos no ambiente do sistema de informações geográficas ILWIS 2.2 para Windows (ITC, 1998).

\subsubsection{Elaboração de Mapa de Uso do Solo e da Vegetação Natural a Partir de Fotografia Aérea de 1978}

Gerou-se uma ortofoto, cujo procedimento pode ser subdividido nas seguintes etapas: digitalização da fotografia aérea através do uso de um scanner; criação de uma georreferência, especificação do sistema de coordenadas e do arquivo do modelo digital do terreno usado; registro das marcas fiduciais, que consiste na especificação da distância focal da câmera (em mm) e das coordenadas de foto (em mm) das marcas fiduciais; e a indicação de pontos de controle detectados na fotografia aérea e em mapa elaborado pela Secretaria de Economia e Planejamento do Estado de São Paulo (escala 1:10000, projeção UTM). Posteriormente, foram digitalizados os polígonos correspondentes aos diversos usos do solo, originando um mapa vetorial e o correspondente mapa raster.

\subsubsection{Processamento de Imagens dos Satélites SPOT e Landsat}

Para obtenção de informações atualizadas sobre o uso do solo e vegetação natural utilizaram-se dados de imagens dos satélites SPOT e Landsat-5. Foram adquiridos dados em formato digital das bandas em modo pancromático $(\mathrm{P})$ do $\operatorname{SPOT}(0,51-0,73 \mu \mathrm{m})$ (passagem do satélite em 01 de setembro de 1997) e multiespectral

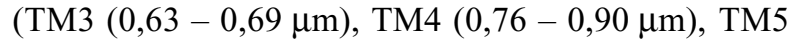
$(1,55-1,75 \mu \mathrm{m})$ ) do Landsat-5 (passagem do satélite em 28 de setembro de 1997). Quando as bandas no modo pancromático do SPOT e multiespectral do Landsat-5 são combinadas, alia-se o maior nível de detalhe de uma resolução de $10 \mathrm{~m}\left(100 \mathrm{~m}^{2}\right)$ com o conteúdo de informações, acrescido a partir de imagens coloridas (multiespectrais). A fusão de imagens de satélite tornou-se muito utilizada pela natureza complementar dos vários conjuntos de dados.

A imagem pancromática do SPOT que englobava a área de estudo foi georreferenciada em relação ao mapa elaborado pela Secretaria de Economia e Planejamento do Estado de São Paulo. A georreferência foi feita no ambiente do ILWIS, através do método de pontos de controle. Os pontos de controle são usados para derivar uma transformação polinomial de primeira (affine), segunda ou terceira ordem. Cada transformação requer um número mínimo de pontos de referência (três para transformação affine, seis para polinomial de segunda ordem e nove para polinomial de terceira ordem). Em caso de mais pontos serem selecionados, os resíduos e a raiz do erro quadrático médio (sigma) podem ser usados para avaliar as equações calculadas e, conseqüentemente, o sucesso do georreferenciamento. Após georreferenciar a imagem, esta apresenta coordenadas para cada pixel, mas sua geometria não está ainda corrigida em relação às distorções geométricas. O processo de geocodificação resulta em uma nova imagem, na qual os pixels são rearranjados de acordo com a geometria do mapa. Para geocodificar a imagem SPOT pancromática utilizou-se, então, o módulo de reamostragem do ILWIS.

As bandas TM3, TM4 e TM5 foram registradas em relação à banda pancromática do SPOT, utilizando-se para isso o módulo de georreferência do ILWIS através de pontos de controle. Através do módulo de reamostragem do ILWIS, processaram-se as bandas TM, de tal maneira que essas tiveram seus pixels diminuídos, ficando do tamanho dos pixels da imagem pancromática do SPOT, preparando-as para fusão. Além disto, passou-se um filtro de suavização (média ponderada) nas bandas TM.

O método de fusão das imagens PAN e TM utilizado foi o do filtro passa altas - HPF (Chavez et al., 1991). 
Aplicou-se um filtro laplaciano na imagem de alta resolução, no caso a SPOT pancromática. Os filtros passa altas eliminam as feições de baixa freqüência, deixando apenas as de alta freqüência, normalmente expressas por bordas ou limites entre áreas de diferentes valores de número digital (DN).

Gerada a composição colorida selecionada, resultante da fusão das bandas multiespectrais do TM e pancromática do SPOT, o mapa com informações atualizadas de uso do solo e da vegetação natural foi derivado dessa imagem. Não se trabalhou com procedimentos de classificação digital. No ambiente do ILWIS, criou-se um sistema de coordenadas (projeção UTM, fuso 22, datum córrego Alegre) e, com a composição na tela, digitalizaram-se os limites dos polígonos correspondentes às classes de uso e ocupação do solo, em face das diferentes cores que aparecem na imagem, que foram associadas a essas classes, após a verificação de campo com o auxílio de GPS. O passo seguinte foi gerar o mapa de polígonos através do módulo de poligonalização do SIG.

\subsubsection{Cruzamento dos Mapas raster do Uso do Solo de 1978 e 1997 e Análise com as Informações de Classe de Declividade e Unidades de Solo}

O mapa temático da variação temporal da vegetação natural foi elaborado através da sobreposição no ILWIS dos dois mapas de uso do solo (1978 e 1997). Foram feitos então os cruzamentos das variáveis ambientais declividade e unidades de solo com essa variação de ocorrência da vegetação na Fazenda Edgardia.

\section{RESULTADOS E DISCUSSÃO}

O mapa temático contendo a informação espacial do histórico recente do uso do solo (1978) é apresentado na Figura 3a. A Figura 3b mostra as classes de uso do solo para o ano de 1997. As classes utilizadas para geração do mapa temático de uso do solo atual foram avaliadas durante todo o processo de digitalização dos limites dos polígonos e de verificação de campo, tendo sido definidas dez classes para a legenda. O Quadro 1 está relacionado aos mapas temáticos da Figura 3a e 3 b e oferece as informações sobre área (ha) de cada classe e as respectivas porcentagens de ocupação, em 1978 e 1997.

A ocupação florestal foi dividida em duas classes, Floresta Estacional Semidecidual e cerradão, resultado alcançado pela identificação de espécies indicadoras de cada tipologia para as duas classes. As áreas de pastagem foram divididas em três classes, e o aspecto de diferenciação tem relação com a ocorrência do componente florestal nas mesmas, resultados adquiridos através de análise da ortofoto e da composição colorida. As áreas de Formação Pioneira Aluvial foram divididas em três classes devido à diferenciação que se mostra nítida na imagem de satélite, em função da presença ou ausência de vegetação natural, ou ainda pela ocorrência de solo nu em locais destinados ao plantio de arroz irrigado.

Quadro 1 - Ocupação das classes de uso do solo da Fazenda Experimental Edgardia, em 1978 e 1997

Table 1 - Land use class occupation at Edgardia Experimental Farm, in 1978 and 1997

\begin{tabular}{|c|c|c|c|c|}
\hline \multirow{2}{*}{ Classe de Uso do Solo } & \multicolumn{2}{|c|}{1978} & \multicolumn{2}{|c|}{1997} \\
\hline & Área (ha) & $\%$ & Área (ha) & $\%$ \\
\hline Floresta Estacional Semidecidual & 437,04 & 37,91 & 613,99 & 53,26 \\
\hline Cerradão & 120,07 & 10,42 & 132,79 & 11,52 \\
\hline Pastagem & 419,25 & 36,37 & 174,41 & 15,13 \\
\hline Pastagem e regeneração vegetação natural & 12,11 & 1,05 & 15,06 & 1,31 \\
\hline Pastagem e árvores esparsas & - & - & 80,41 & 6,98 \\
\hline Formação Pioneira Aluvial & 1,76 & 0,15 & 43,94 & 3,81 \\
\hline Várzea & 107,88 & 9,36 & 29,19 & 2,53 \\
\hline Solo nu em várzea & - & - & 34,86 & 3,02 \\
\hline Cultura agrícola & 8,84 & 0,77 & 10,85 & 0,94 \\
\hline Solo nu & 45,82 & 3,97 & 17,27 & 1,50 \\
\hline Total & $1.152,77$ & 100,00 & $1.152,77$ & 100,00 \\
\hline
\end{tabular}


a

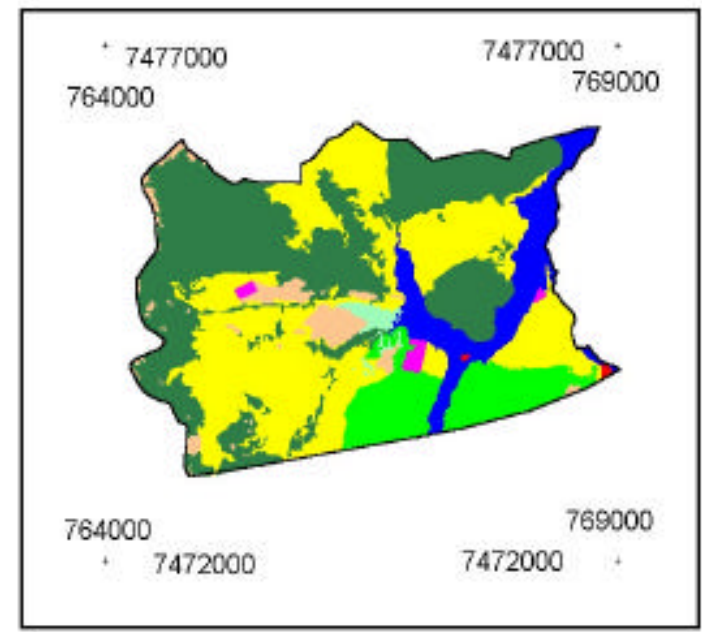

b

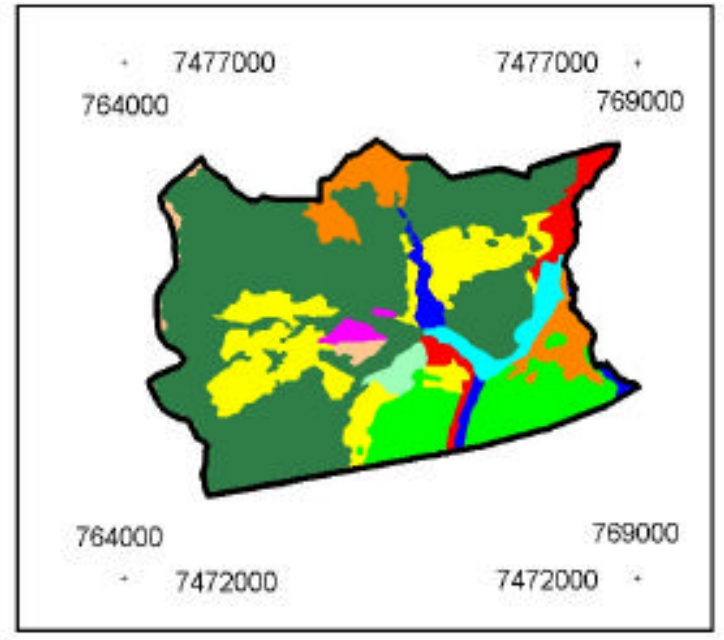

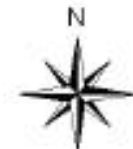

$5 \longdiv { 1 5 0 0 \mathrm { m } }$

\section{Legenda}

Floresta Estacional Semidecidual

cerradão

pastagem

pastagem e regeneraçāo vegetaçäo natural

Formaçăo Pioneira Aluvial

varizea

cultura agricola

solo nu

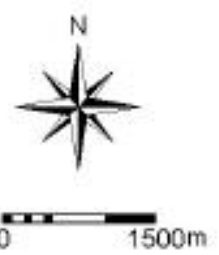

\section{Legenda}

Floresta Estacional Semidecidual

cerradāo

pastagem

pastagem e regeneraçäo vegetaçāo natural

pastagem e árvores esparsas

- Formação Pioneira Aluvial

- várzea

$\square$ solo nu em várzea

$\square$ cultura agricola

solo nu

Figura 3 - a. Mapa de uso do solo da Fazenda Edgardia em 1978 e b. mapa de uso do solo da Fazenda Experimental Edgardia em 1997.

Figure 3 - a. Land use map of Edgardia Farm, in 1978; b. land use map of Edgardia Farm, in 1997.

Pelo cruzamento dos mapas raster do uso do solo de 1978 e 1997, gerou-se o mapa que apresenta a variação temporal das áreas dos fragmentos de vegetação natural em um período de 19 anos (Figura 4). O Quadro 2 oferece as informações sobre as áreas (ha) das classes de ocorrência da vegetação natural em função da variação temporal, relacionadas ao mapa temático.

Ao avaliar a variação temporal da vegetação natural no período de 19 anos, constatou-se um balanço positivo principalmente nas classes de Floresta Estacional Semidecidual, com variação porcentual de 37,91 para 53,26. A área de cerradão apresentou variação porcentual de 10,42 para 11,52. Esses resultados caracterizam a ocorrência do processo de regeneração natural da vegetação florestal na Fazenda Edgardia, que preferencialmente ocorreu em áreas de pastagem e cuja redução porcentual foi de 36,37 para 15,13 .

Nas associações entre a variação temporal da vegetação e a declividade destacam-se: 1) floresta estacional nos dois períodos e classes de declividade $10-20 \%, 20$ - $40 \%$ e $\geq 40 \%$ (relevo ondulado a escarpado), respectivamente $15,67,19,06$ e $11,08 \%$ dos cruzamentos realizados, caracterizando a ocorrência de vegetação natural na frente da Cuesta; 2) Floresta Estacional Semidecidual em 

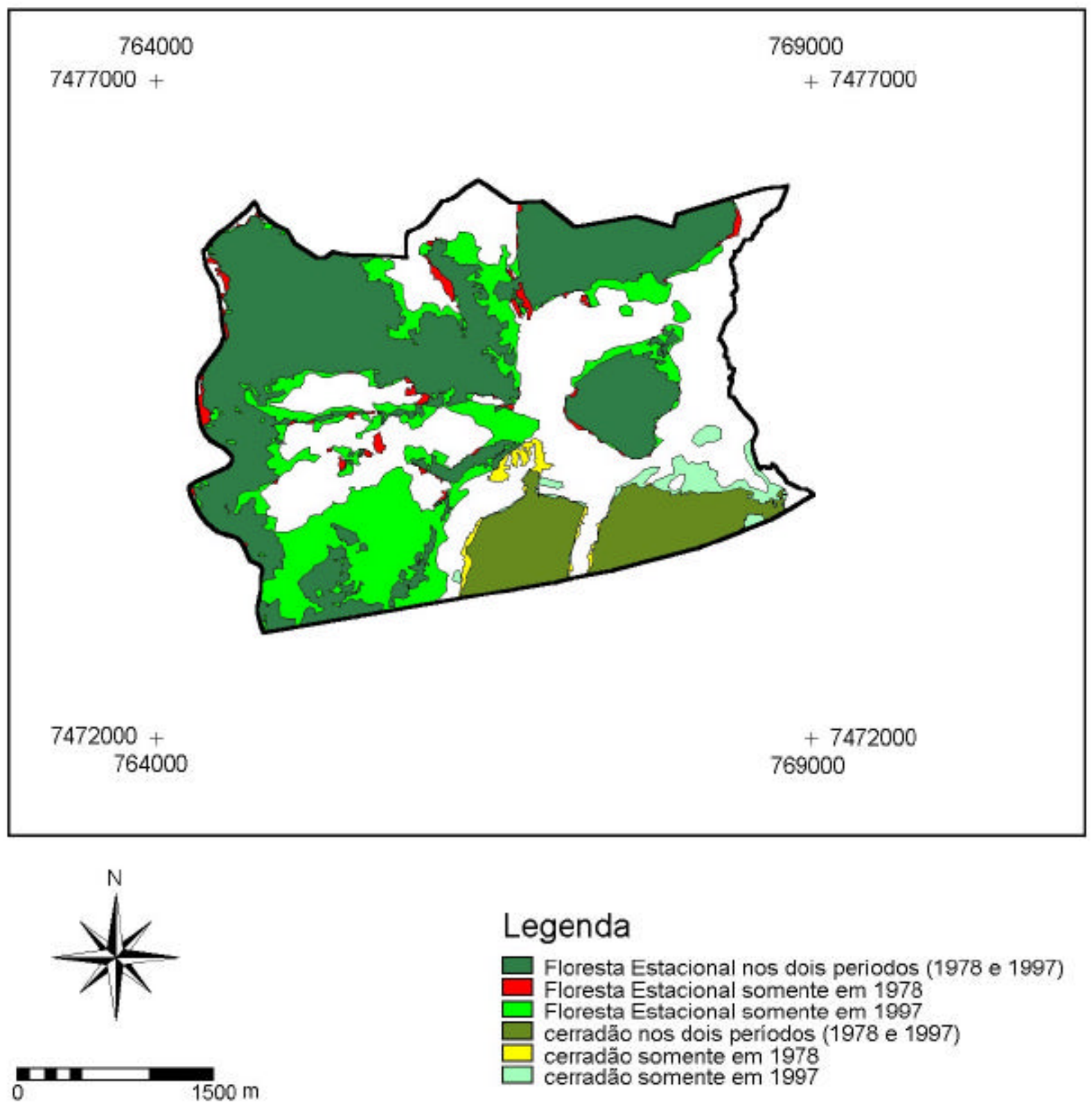

Figura 4 - Mapa da variação temporal de ocorrência da vegetação natural na Fazenda Edgardia. Figure 4 - Thematic map of temporal variation of natural vegetation occurrence at Edgardia Farm.

1997 (áreas com regeneração) e classe de declividade $10-20 \%$ (relevo ondulado), compondo $10,17 \%$ dos cruzamentos realizados; e 3) cerradão nos dois períodos e classe de declividade 02 - 10\% (relevo suave ondulado), com $8,8 \%$ dos cruzamentos realizados, que se caracteriza por ocorrer na depressão periférica.
As principais associações entre a variação temporal da vegetação natural e as unidades de solos são: 1) Floresta Estacional Semidecidual nos dois períodos com Neossolo Litólico, solo raso, porém de boa fertilidade, atingindo $40,52 \%$ dos cruzamentos realizados no ILWIS, associação que ocorre principalmente na frente da Cuesta; 
Quadro 2 - Ocorrência da vegetação natural em função da variação temporal Table 2 -Occurrence of natural vegetation correlated with temporal variation

\begin{tabular}{|l|r|}
\hline \multicolumn{1}{|c|}{ Ocorrência } & Área (ha) \\
\hline Floresta Estacional Semidecidual nos dois períodos (1978 e 1997) & 420,68 \\
\hline Floresta Estacional Semidecidual somente em 1978 & 16,36 \\
\hline Floresta Estacional Semidecidual somente em 1997 & 193,30 \\
\hline Cerradão nos dois períodos (1978 e 1997) & 110,15 \\
\hline Cerradão somente em 1978 & 9,92 \\
\hline Cerradão somente em 1997 & 22,64 \\
\hline
\end{tabular}

2) Floresta Estacional Semidecidual em 1997 (áreas com regeneração) com Neossolo Litólico, com 7,17\% dos cruzamentos realizados; e 3) cerradão nos dois períodos e Neossolo Quartzarênico órtico, perfazendo 10,52\% dos cruzamentos realizados, associação típica que se verifica na depressão periférica da Cuesta.

\section{CONCLUSÕES}

1. Na dinâmica da vegetação natural que ocorre na Fazenda Edgardia, analisado o intervalo de 19 anos entre as informações de uso e ocupação do solo (de 1978 e 1997), houve regeneração significativa de áreas da classe Floresta Estacional Semidecidual e pequena regeneração de áreas da classe cerradão.

2. Para as áreas que se mantiveram com Floresta Estacional Semidecidual no intervalo de 19 anos, as principais associações ocorreram com as classes de declividade $10-20 \%, 20-40 \%$ e $\geq 40 \%$ (relevo ondulado a escarpado) e com Neossolos Litólicos. Tanto o relevo quanto solo são característicos da frente da Cuesta de Botucatu.

3. A regeneração da Floresta Estacional Semidecidual processou-se em relevo ondulado e sobre Neossolo Litólico, ou seja, aconteceu principalmente na frente da Cuesta.

4. Para áreas que se mantiveram com a classe cerradão no intervalo de 19 anos, as principais associações ocorreram com a classe de declividade $02-10 \%$ (relevo suave-ondulado) e classe de solo Neossolo Quartzarênico órtico, que são típicas da depressão periférica da Cuesta de Botucatu.

5. Constatou-se que realmente a frente da Cuesta pode ser uma área importante na ligação de fragmentos de vegetação natural, não só na Fazenda Experimental Edgardia, como também em toda a Cuesta de Botucatu.

\section{AGRADECIMENTO}

À Fundação de Amparo à Pesquisa do Estado de São Paulo - FAPESP (processo no 98/15074-8), pelo valioso auxílio.

Ao grande companheiro de andanças pela Fazenda Edgardia, Aparecido Agostinho Arruda. Espero que com o nosso labor possamos manter viva a memória de tantas pessoas que já trabalharam naquele pedaço de chão.

\section{REFERÊNCIAS BIBLIOGRÁFICAS}

CARVAlHO, W. A.; PANOSO, L. A.; MORAES, M. H. Levantamento semidetalhado dos solos da Fazenda Experimental Edgardia - Município de Botucatu. Botucatu: Faculdade de Ciências Agronômicas - UNESP, 1991. 467 p. (Boletim Científico, v. 2, n. 1/2)

CHAVEZ, P. S.; SIDES, S. C.; ANDERSON, J. A. Comparison of three different methods to merge multiresolution and multispectral data: Landsat TM and SPOT panchromatic. Photogrammetric Engineering and Remote Sensing, v. 57, n. 3, p. 295-303, 1991.

VELOSO, H. P. (Org). Manual técnico da vegetação brasileira. Rio de Janeiro: IBGE/Departamento de Recursos Naturais e Estudos Ambientais, 1992. 93 p.

INTERNATIONAL INSTITUTE FOR AEROSPACE SURVEY \& EARTH SCIENCES - ITC. ILWIS 2.2 for Windows: User's Guide. Enschede: ITC, 1998. 511 p.

ORTEGA,V. R.; ENGEL, V. L. Conservação da biodiversidade de remanescentes de Mata Atlântica na região de Botucatu, SP. In: CONGRESSO NACIONAL SOBRE ESSÊNCIAS NATIVAS, 2., 1992, São Paulo. Anais... São Paulo: Revista do Instituto Florestal, 1992. v. 4. p. $839-852$. 